\title{
Engaging communication experts in a Delphi process to identify patient behaviors that could enhance communication in medical encounters
}

\author{
Jaya K Rao*1, Lynda A Anderson², Bhuvana Sukumar³, Danielle A Beauchesne 3 , Terry Stein ${ }^{4}$ and Richard M Frankel ${ }^{5}$
}

\begin{abstract}
Background: The communication literature currently focuses primarily on improving physicians' verbal and nonverbal behaviors during the medical interview. The Four Habits Model is a teaching and research framework for physician communication that is based on evidence linking specific communication behaviors with processes and outcomes of care. The Model conceptualizes basic communication tasks as "Habits" and describes the sequence of physician communication behaviors during the clinical encounter associated with improved outcomes. Using the Four Habits Model as a starting point, we asked communication experts to identify the verbal communication behaviors of patients that are important in outpatient encounters.
\end{abstract}

Methods: We conducted a 4-round Delphi process with 17 international experts in communication research, medical education, and health care delivery. All rounds were conducted via the internet. In round 1, experts reviewed a list of proposed patient verbal communication behaviors within the Four Habits Model framework. The proposed patient verbal communication behaviors were identified based on a review of the communication literature. The experts could: approve the proposed list; add new behaviors; or modify behaviors. In rounds 2, 3, and 4, they rated each behavior for its fit (agree or disagree) with a particular habit. After each round, we calculated the percent agreement for each behavior and provided these data in the next round. Behaviors receiving more than $70 \%$ of experts' votes (either agree or disagree) were considered as achieving consensus.

Results: Of the 14 originally-proposed patient verbal communication behaviors, the experts modified all but 2, and they added 20 behaviors to the Model in round 1. In round 2, they were presented with 59 behaviors and 14 options to remove specific behaviors for rating. After 3 rounds of rating, the experts retained 22 behaviors. This set included behaviors such as asking questions, expressing preferences, and summarizing information.

Conclusion: The process identified communication tasks and verbal communication behaviors for patients similar to those outlined for physicians in the Four Habits Model. This represents an important step in building a single model that can be applied to teaching patients and physicians the communication skills associated with improved satisfaction and positive outcomes of care.

\section{Background}

Patient-physician communication is recognized as an important aspect of health care quality and patient safety $[1,2]$. The number of investigations examining strategies to enhance physician-patient communication is growing. For example, a recent systematic review identified 36 ran-

* Correspondence: jayarao@unc.edu

${ }^{1}$ Division of Pharmaceutical Outcomes and Policy, Eshelman School of

Pharmacy, University of North Carolina at Chapel Hill, 2202 Kerr Hall, CB 7573, Chapel Hill, NC 27599, USA

Full list of author information is available at the end of the article domized controlled trials of interventions designed to enhance physician or patient communication behaviors [3]. These interventions generally resulted in improved communication behaviors among physicians and patients. In particular, physicians in the intervention groups often received higher ratings of their overall communication style and exhibited specific patient-centered communication behaviors more often than those in the control groups. Similarly, intervention patients obtained 
more information from their physicians and exhibited greater involvement during visits than controls [3].

Although prior investigations have demonstrated substantial progress in improving specific communicative behaviors of physicians and patients, they have tended to focus exclusively on either the physician or patient, and do not examine how the physician's and patient's communication behaviors relate to each other during the interaction. These limitations were noted by Inui and colleagues in 1985 [4], and to a certain extent, may result from the lack of an overarching framework that describes the sequence of physician and patient communication behaviors as they might occur during the course of a clinical visit.

The Four Habits Model addresses these concerns by focusing on how temporal and sequential elements of the encounter relate to each another and to outcomes (Table 1) [5-9]. This framework identifies the basic communication tasks of the clinical encounter and conceptualizes how these tasks or "habits" relate to one another during the visit. The four habits include: Invest in the beginning (Habit 1), Elicit the patient's perspective (Habit 2), Demonstrate empathy (Habit 3), and Invest in the end (Habit 4). Each habit includes a group of physician communication behaviors and skills that are associated with effective clinical practice and positive health outcomes $[7,8]$.

The Four Habits Model has recently been validated and is being used in physician education and research. In particular, the model has been used to teach clinicians in different stages of training and specialties (e.g., medical students, general practitioners, geriatricians), and has been adapted to a variety of communication topics, such as end-of-life issues, cultural competence, and costrelated conversations [8,9]. Investigators have also used the Four Habits Model to evaluate the communication practices of physicians with exceptional patient satisfaction ratings [10] and assess the communication skills of physicians who practice in other countries [11].

We were interested in obtaining expert opinion on adapting the Four Habits Model to make it more clearly reflective of the patient's side of the physician-patient interaction. To begin this task, we involved international and national experts in communication research in a consensus-building process. The experts were asked, "Which patient verbal communication behaviors should be added to the Four Habits Model so that it reflects the interactive nature of communication between physicians and patients?" We describe our approach and findings and discuss the implications of our results. We also explore potential next steps to move the field of patient-physician communication research forward.

\section{Methods}

The Delphi method was the central approach used in this study. This method was first developed in the early 1950s as a tool for setting military priorities and since then, has been used to solve a variety of problems, such as helping groups develop educational priorities, performance indicators, and treatment guidelines [12-16]. Based on the premise that pooled intelligence enhances individual judgment and captures the collective opinion of experts $[12,14,15]$, the Delphi technique is valued for its ability to structure and organize group communication [16]. The process typically involves multiple interactions with participants who complete two or more rounds of surveys over a relatively short period of time $[14,15,17,18]$.

Although there are other methods that help facilitate consensus among experts $[13,19,20]$, the Delphi technique's characteristics of expert anonymity and structured communication offer a number of specific advantages. The process allows experts who are in geographically-distinct locations to participate over time, and as a result, is more cost-effective (in terms of time and expense) than convening multiple face-to-face meetings $[15,18,19]$. Because they participate in the rounds asynchronously, the experts have an opportunity to consider the issue and provide their input without time or group pressures $[14,18]$. Moreover, the structured communication feature of the Delphi method helps facilitate group consensus, or score stability, while avoiding interpersonal influences $[12,14,16]$. Finally, this process is known to conclude with a moderate perceived sense of closure and accomplishment among participants [21]. Figure 1 illustrates the steps of the Delphi technique employed in this project. The study was reviewed and approved by the Centers for Disease Control and Prevention according to the Department of Health and Human Services Policy for Protection of Human Research Subjects.

The first phase involved nominating experts to participate in the Delphi process. Three members of the project team (JKR, LAA, RMF) identified a group of experts in patient-physician communication. The group included international researchers who have conducted patient or physician communication interventions, medical educators, and experts in health services delivery and patientcentered care (e.g., health services researchers, health care administrators). Our invitation contained information on the Four Habits Model, Delphi method, and purpose of our project. Those who accepted our invitation were informed that they were required to respond to the first round in order to participate in subsequent rounds of ratings.

Three members of the project team (JKR, BS, DB) oversaw all four rounds of the Delphi process. The entire process took place between January 15 and May 2, 2008 and 
Table 1: The Four Habits Model

\begin{tabular}{|c|c|c|c|}
\hline Habit & Skills & Techniques \& Examples & Pay-off \\
\hline \multirow[t]{3}{*}{$\begin{array}{l}\text { Invest in the } \\
\text { beginning }\end{array}$} & $\begin{array}{l}\text { Create rapport } \\
\text { quickly }\end{array}$ & $\begin{array}{l}\text { - Introduce self to everyone in the room } \\
\text { - Acknowledge wait } \\
\text { - Convey knowledge of patient's history by } \\
\text { commenting on prior visit or problem } \\
\text { - Attend to patient's comfort } \\
\text { - Make a social comment or ask a non-medical } \\
\text { question to put patient at ease } \\
\text { - Adapt own language, pace, and posture in } \\
\text { response to patient }\end{array}$ & $\begin{array}{l}\text { - Establishes a welcoming atmosphere } \\
\text { - Allows faster access to real reason for visit } \\
\text { - Increases diagnostic accuracy } \\
\text { - Requires less work } \\
\text { - Minimizes "Oh, by the way..." at the end of the visit } \\
\text { - Facilitates negotiating an agenda }\end{array}$ \\
\hline & $\begin{array}{l}\text { Elicit the } \\
\text { patient's } \\
\text { concerns }\end{array}$ & $\begin{array}{l}\text { - Start with open-ended questions: } \\
\text { - "What would you like help with today?" or, } \\
\text { - "I understand you're here for... Could you tell me } \\
\text { more about that?" or, } \\
\text { - What else?" } \\
\text { - Speak directly with the patient when using an } \\
\text { interpreter }\end{array}$ & \\
\hline & $\begin{array}{l}\text { Plan the visit } \\
\text { with the } \\
\text { patient }\end{array}$ & $\begin{array}{l}\text { - Repeat concerns back to check understanding } \\
\text { - Let patient know what to expect: "How about if we } \\
\text { start with talking more about...then, I'll do an exam, } \\
\text { and then we'll go over possible tests/ways to treat } \\
\text { this? Sound OK?" } \\
\text { - Prioritize when necessary: "Let's make sure we talk } \\
\text { about X and Y. It sounds like you also want to make } \\
\text { sure we cover Z. If we can't get to the other concerns, } \\
\text { lets..." }\end{array}$ & \\
\hline $\begin{array}{l}\text { Elicit the } \\
\text { patient's } \\
\text { perspective }\end{array}$ & $\begin{array}{l}\text { Ask for } \\
\text { patient's } \\
\text { ideas }\end{array}$ & $\begin{array}{l}\text { - Assess patient's point of view: } \\
\text { - "What do you think is causing your symptoms?" } \\
\text { - "What worries you most about this problem?" } \\
\text { - Ask about ideas from significant others }\end{array}$ & $\begin{array}{l}\text { - Respects diversity } \\
\text { - Allows patient to provide important diagnostic } \\
\text { clues } \\
\text { - Uncovers hidden concerns } \\
\text { - Reveals use of alternative treatments or requests } \\
\text { for tests } \\
\text { - Improves diagnosis depression and anxiety }\end{array}$ \\
\hline
\end{tabular}

Elicit specific - Determine patient's goal in seeking care: requests "When you've been thinking about this visit, how were you hoping I could help?"

Explore the impact on the patient's life
- Check context: "How has the illness affected your daily activities, work, or family?"
- Establishes a welcoming atmosphere

- Increases diagnostic accuracy

quires less work

- Minimizes "Oh, by the way..." at the end of the visit

Facilitates negotiating an agenda 
Table 1: The Four Habits Model (Continued)

\begin{tabular}{|c|c|c|c|}
\hline & $\begin{array}{l}\text { Make at least } \\
\text { one empathic } \\
\text { statement }\end{array}$ & $\begin{array}{l}\text { - Name a likely emotion: "That sounds really } \\
\text { upsetting." } \\
\text { •Compliment patients on efforts to address problem }\end{array}$ & - Makes limit-setting or saying "no" easier \\
\hline & $\begin{array}{l}\text { Be aware of } \\
\text { your own } \\
\text { reactions }\end{array}$ & $\begin{array}{l}\text { - Use own emotional response as a clue to what } \\
\text { patient might be feeling } \\
\text { - Take a brief break if necessary }\end{array}$ & \\
\hline \multirow[t]{4}{*}{$\begin{array}{l}\text { Invest in the } \\
\text { end }\end{array}$} & $\begin{array}{l}\text { Deliver } \\
\text { diagnostic } \\
\text { information }\end{array}$ & $\begin{array}{l}\text { - Frame diagnosis in terms of patient's original } \\
\text { concerns } \\
\text { - Test patient's comprehension } \\
\text { - Improves adherence }\end{array}$ & $\begin{array}{l}\text { - Increases potential for collaboration } \\
\text { - Influences health outcomes } \\
\text { - Improves adherence } \\
\text { - Reduces return calls and visits }\end{array}$ \\
\hline & $\begin{array}{l}\text { Provide } \\
\text { education }\end{array}$ & $\begin{array}{l}\text { - Explain rationale for tests and treatments } \\
\text { - Review possible side effects and expected course of } \\
\text { recovery } \\
\text { - Recommend lifestyle changes } \\
\text { - Provide written materials and refer to other sources }\end{array}$ & Encourages self care \\
\hline & $\begin{array}{l}\text { Involve patient } \\
\text { in } \\
\text { decision } \\
\text { making }\end{array}$ & $\begin{array}{l}\text { - Discuss treatment goals } \\
\text { - Explore options, listening for the patient's } \\
\text { preferences } \\
\text { - Set limits respectfully: "I can understand how } \\
\text { getting that test makes sense to you. From my point } \\
\text { of view, since the results won't help us diagnose or } \\
\text { treat your symptoms, I suggest we consider this } \\
\text { instead." } \\
\text { - Assess patient's ability and motivation to carry out } \\
\text { plan }\end{array}$ & \\
\hline & $\begin{array}{l}\text { Complete the } \\
\text { visit }\end{array}$ & $\begin{array}{l}\text { - Ask for additional questions: "What questions do } \\
\text { you have?" } \\
\text {-Assess satisfaction: "Did you get what you needed?" } \\
\text { • Reassure patient of ongoing care }\end{array}$ & \\
\hline
\end{tabular}

${ }^{\Theta} 1996,1999,2003$ by The Permanente Medical Group, Inc., Physician Education and Development Rao et al. BMC Health Services Research 2010 10:97 doi:10.1186/1472-6963-10-97

was conducted using Survey Monkey, a web-based survey and data collection system. In round 1 , we provided the experts with a slightly modified version of the Four Habits Model that only contained physician verbal communication behaviors (i.e., non-verbal behaviors such as "convey empathy non-verbally" were not included) and a list of proposed patient verbal communication behaviors (herein referred to as "patient behaviors") within each habit. The proposed list of patient behaviors was based on our review of communication interventions directed toward patients and consisted of the verbal communica- tion outcomes reported in these studies [3]. The participants were reminded that our goal was to identify patient behaviors to add to the Four Habits Model so it would be more reflective of the interactional nature of physicianpatient communication. They were asked to review the list of proposed patient behaviors and indicate if it was complete. If a participant thought the list was incomplete, he or she was asked to add specific behaviors to the framework. Additionally, participants could change the wording of the proposed behaviors or move behaviors between habits. With each of these options, we empha- 


\section{Define problem}

Which patient verbal communicative behaviors should be added to the Four Habits Model so it reflects the interactional nature of physician-patient communication?

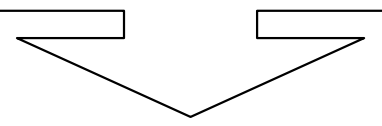

\section{I dentify and invite experts}

Expertise in medical education, physician or patient communication research, health care delivery

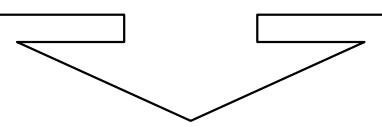

\section{Round 1: solicit ideas}

Provided with a list of 14 proposed patient behaviors within Four Habits Model. Asked to modify or add behaviors to the Model or approve the list as complete

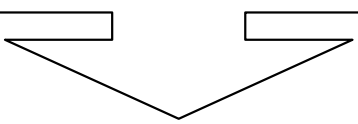

\section{Round 2: rate ideas}

Rate each behavior for fit with the Four Habits Model.

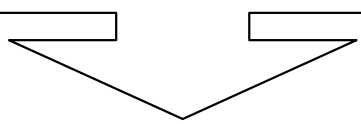

\section{Round 3: rate ideas}

Review Round 2 ratings. Re-rate each behavior for fit with the Four Habits Model.

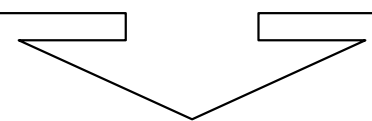

\section{Round 4: rate ideas}

Review Round 2 and 3 ratings. Re-rate each behavior for fit with the Four Habits Model and provide qualitative feedback on behaviors.

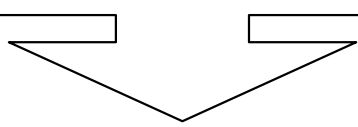

\section{Final review}

Provide feedback on final list of behaviors and on the entire Delphi process. 
sized our focus on identifying measurable verbal communicative behaviors within the framework and asked that their suggestions meet this requirement.

In rounds 2, 3 and 4, the participants were instructed to consider the behaviors originally proposed by the project team and the behaviors they added or modified in round 1. For the originally-proposed behaviors and suggested additions, they were asked to indicate whether each behavior fit within the associated habit (agree or disagree). For behaviors with suggested modifications, the participants could choose to retain the behavior in its original form, select one of the modifications, or remove the behavior from the habit.

After each round, we calculated the percent agreement for each behavior and presented these data in the next round. We asked the participants to review this information and re-rate each behavior for its fit with the habit. The literature on the Delphi method suggests that investigators establish decision rules regarding the handling of rating information and the definition of consensus a priori $[13,15,16]$; defining consensus based on a specific percentage level is a common approach [16]. Thus, before this study began, we established that behaviors that received greater than $70 \%$ of the experts' votes as achieving consensus. Once this level was reached, these behaviors were not included in subsequent rounds of ratings. Behaviors that received 0 votes were also excluded from subsequent rounds (i.e., reached consensus to drop). For the suggested additions, if more than $70 \%$ of the experts agreed that a behavior fit the habit, it was retained (i.e., achieved consensus to retain); if less than 30\% agreed that a behavior fit the habit, it was dropped (i.e., achieved consensus to drop). For combinations of originally-proposed behaviors with suggested modifications, only the choices that received 0 votes were dropped from the subsequent round. The remaining items were included in the next rounds until one of the options in the set received more than $70 \%$ of the experts' votes or until the entire rating process was concluded.

In round 4, we presented all behaviors that achieved consensus and rating data for the behaviors that did not achieve consensus. In this round, the experts were given a final opportunity to rate and comment on the behaviors that had not achieved consensus in round 3. After round 4 , the project team collated the rating data from all rounds to develop a list of behaviors that did and did not reach consensus. The experts were invited to provide feedback on the list and the overall Delphi process.

\section{Results}

We invited 31 international experts in patient-physician communication to participate in the Delphi process. This group included 17 physicians (training: 13 internal medicine, 3 family practice, 1 anesthesiology), $13 \mathrm{PhD}$ scien- tists (training: 8 psychology, 2 communication research, 1 public health, 2 health services research), and 1 physician assistant. In the United States (US), a physician assistant is a health professional who is licensed to provide basic medical services under the supervision of a licensed physician. Of these individuals, 5 declined ( 2 internists, 2 family practitioners, $1 \mathrm{PhD}$ (psychology)) and $3 \mathrm{PhD}$ scientists (public health, communication research, health services research) did not respond to our invitation. Thus, 23 experts responded to our initial invitation and agreed to participate; this group was balanced with respect to gender (11 females, 12 males) and included 5 individuals from countries outside of US. In terms of educational background, 13 were physicians (11 internists, 1 family practice, 1 anesthesiologist), with 1 physician assistant and $9 \mathrm{PhD}$ scientists (7 psychology, 1 communication research, 1 health services research).

Of the 23 experts, 17 responded to round 1 and were invited to participate in the subsequent rounds. Overall, this group included 11 males and 3 individuals from nonUS countries and was comprised of 9 physicians (8 internists, 1 family practitioner), $7 \mathrm{PhDs}$ (5 psychology, 1 health services research, 1 communication research) and 1 physician assistant. The 6 experts ( 4 physicians ( 3 internists, 1 anesthesiologist), $2 \mathrm{PhD}$ (psychology)) who did not respond to round 1 were not involved in subsequent rounds.

Round 1 of the Delphi process began with 14 patient behaviors that were proposed by the project team. In this round, the 17 experts accepted 2 of the proposed behaviors, modified the remaining 12 behaviors, and added 20 new behaviors to the model (Table 2). Of the 20 suggested additions, 5 were added to Habit 1, 6 to Habit 2, 4 to Habit 3, and 5 to Habit 4. The experts proposed a total of 25 modifications to the original 12 behaviors, ranging from 1 to 4 modifications per behavior. Some of the modifications consisted of minor wording changes (i.e., "share" instead of "disclose" all relevant concerns) while other suggestions were more extensive (change "tell story" to "tell story with answers to Kleinman's explanatory model [22]"). Overall, the experts directed most suggestions to Habit 2 (12 modifications and 6 additions), with the fewest suggestions made to Habit 3 (2 modifications and 4 additions).

Based on input from round 1, the 17 experts were presented with 59 behaviors in round 2 along with 14 options to remove specific behaviors from habits (Table $3)$. Of the behaviors presented, 10 behaviors reached consensus (i.e., 12 or more experts agreed that the behavior fit the habit) and were retained (Table 3, round 2 (column $2)$ ). The retained behaviors were in Habits 2 (4 behaviors) or Habit 4 (6 behaviors). At the same time, 11 items were dropped ( 8 received 0 votes and 3 received votes from 5 or fewer experts. All 17 experts responded to round 2. 
Table 2: Results from round 1 of the Delphi process

\begin{tabular}{|c|c|c|}
\hline Habit & $\begin{array}{l}\text { Proposed list of patient } \\
\text { behaviors (original) }\end{array}$ & Changes suggested in Round 1 \\
\hline \multirow[t]{14}{*}{$\begin{array}{l}\text { Invest in the } \\
\text { beginning }\end{array}$} & Make personal remarks & $\begin{array}{l}\text { Modifications } \\
\text { Respond to clinician's welcome }\end{array}$ \\
\hline & & Engage in social talk until comfortable \\
\hline & & Return the physician's greeting \\
\hline & Disclose relevant concerns & Modifications \\
\hline & & Disclose all relevant concerns to the best of my knowledge \\
\hline & & Share all relevant concerns \\
\hline & Articulate priorities & Modification \\
\hline & & State which concerns are most important \\
\hline & & Additions \\
\hline & & Approve or modify stated agenda for the visit \\
\hline & & Set the agenda for the visit \\
\hline & & Solicit physician's goals for the visit \\
\hline & & Explain how one learns best \\
\hline & & Greet or verbally welcome physicians \\
\hline \multirow[t]{23}{*}{$\begin{array}{l}\text { Provide your } \\
\text { perspective* }\end{array}$} & Express preferences & $\begin{array}{l}\text { Modification } \\
\text { Share values }\end{array}$ \\
\hline & Express expectations & Modifications \\
\hline & & State specific requests \\
\hline & & Share wishes and expectations \\
\hline & & Express hopes, desires, expectations \\
\hline & Describe impact & Modification \\
\hline & & Tell how illness affects daily life \\
\hline & Participate in the visit & Modifications \\
\hline & & $\begin{array}{l}\text { Provide details about symptoms, concerns, and previous } \\
\text { treatments }\end{array}$ \\
\hline & & Give opinions about possible causes of illness \\
\hline & & $\begin{array}{l}\text { Answer questions in reasonable detail, raise new comments, } \\
\text { demonstrate respect }\end{array}$ \\
\hline & Tell story & Modifications \\
\hline & & Offer information about medical history \\
\hline & & Tell the whole story of illness \\
\hline & & Tell the whole story of your concern(s) \\
\hline & & Tell story with answers to Kleinman's explanatory model \\
\hline & & Additions \\
\hline & & Explain personal beliefs or worries about symptoms \\
\hline & & Honestly point out when areas are left unaddressed \\
\hline & & $\begin{array}{l}\text { State own understanding of problem (explanatory model) to the } \\
\text { physician }\end{array}$ \\
\hline & & Give frank opinions about choices offered \\
\hline & & Offer explanations \\
\hline & & Ask questions about explanations and choices \\
\hline
\end{tabular}


Table 2: Results from round 1 of the Delphi process (Continued)

\begin{tabular}{|c|c|c|}
\hline Communicate & Express feelings and concerns & Modifications \\
\hline about your feelings & & Discuss psychosocial issues and express feelings and concerns \\
\hline \multirow[t]{6}{*}{ and concerns* } & & Express and elaborate on feelings and concerns \\
\hline & & Additions \\
\hline & & Explore impact of feelings and concerns on health \\
\hline & & Respond to physician expression of empathy \\
\hline & & Talk openly about psychosocial issues \\
\hline & & Listen to physician for understanding \\
\hline \multirow[t]{15}{*}{ Invest in the end } & Use own language and terms & Modification \\
\hline & to describe diagnosis & $\begin{array}{l}\text { Use own language and terms to describe diagnosis, evaluation or } \\
\text { treatment plans }\end{array}$ \\
\hline & Participate in decision making & Modifications \\
\hline & & $\begin{array}{l}\text { Express level of participation in decision making desired and } \\
\text { participate to that extent }\end{array}$ \\
\hline & & Make opinions or concerns about choices known \\
\hline & & State preferences about tests or treatment options \\
\hline & Ask questions & No modifications suggested \\
\hline & Seek clarifying information & No modifications suggested \\
\hline & $\begin{array}{l}\text { Restate recommendations and } \\
\text { information provided by doctor }\end{array}$ & $\begin{array}{l}\text { Modification } \\
\text { Restate decisions made during the visit }\end{array}$ \\
\hline & & Additions \\
\hline & & Describe any barriers to following the treatment plan \\
\hline & & Ask the doctor to explain any words or ideas that are confusing \\
\hline & & Explore barriers to implementing the plan \\
\hline & & $\begin{array}{l}\text { Answer the "Ask me } 3 \text { " questions (e.g., "What is my main } \\
\text { problem?", "What do I need to do?", "Why is it important for me to } \\
\text { do this?") }\end{array}$ \\
\hline & & Ask about options interested in but not mentioned by the doctor \\
\hline
\end{tabular}

*Names of Habit 2 (Elicit the patient's perspective) and Habit 3 (Demonstrate empathy) were modified to reflect the health consumer's perspective

In Round 3, the 17 experts were presented with 42 behaviors and 4 options to remove specific behaviors, and they were asked to re-rate these items. Another 8 behaviors (i.e., 6 additions, 1 modification, and 1 originally-proposed behavior) received 12 or more of the experts' votes and were retained (Table 3 , round 3 (column 3 )). Six behaviors were dropped ( 2 received votes from 4 or fewer experts and 4 received 0 votes). Additionally, 3 behaviors were dropped at this point because they were part of a set in which a related behavior reached consensus. Sixteen of the 17 experts responded to round 3; 1 physician (an internist) did not respond to this round.

In Round 4, the 17 experts were asked to rate the remaining 25 behaviors and 4 remove options. At this time, an additional 4 behaviors ( 2 original, 1 modification, 1 addition) received 12 or more of the experts' votes and were retained while 6 behaviors and 2 remove options were dropped (Table 3, round 4 (column 4)). During this round, the experts also had an opportunity to provide feedback on the 25 behaviors being rated. Some commented that there were overlaps between the behaviors they were rating with behaviors that had already reached consensus in prior rounds or certain habits already contained too many consensus behaviors. Other experts expressed concerns with the wording of specific choices or that a particular behavior (for example, "explore impact of feelings on health") would place a significant burden on the patient or might represent an unrealistic expectation for typical patients. Sixteen of the 17 experts responded to round 3; 1 physician (an internist) did not respond to this round.

After 3 rounds of rating, the experts came to consensus on 22 behaviors to retain in the framework (Table 3, final results (column 5)). These behaviors were distributed 
Table 3: Results of the Delphi ratings by round

\begin{tabular}{|c|c|c|c|c|}
\hline Items after Round 1* & $\begin{array}{l}\text { Round 2** } \\
(n=17)\end{array}$ & $\begin{array}{l}\text { Round 3** } \\
(n=16)\end{array}$ & $\begin{array}{l}\text { Round 4** } \\
(n=16)\end{array}$ & Final result \\
\hline \multicolumn{5}{|l|}{ Habit 1: Invest in the beginning } \\
\hline Make personal remarks (original) & $1 / 17+$ & 0 & Drop & Drop \\
\hline Respond to clinician's welcome (modification) & $7 / 17$ & $8 / 16$ & $8 / 16$ & -- \\
\hline Engage in social talk until welcome (modification) & $4 / 17$ & $2 / 16$ & $2 / 16$ & -- \\
\hline Return the physician's greeting (modification) & $3 / 17$ & $3 / 16$ & $2 / 16$ & -- \\
\hline Remove "make personal remarks" from this habit & $2 / 17$ & $3 / 16$ & $4 / 16$ & -- \\
\hline Disclose relevant concerns (original) & $6 / 17$ & $1 / 16$ & Drop & Drop \\
\hline $\begin{array}{l}\text { Disclose all relevant concerns to the best of my } \\
\text { knowledge (modification) }\end{array}$ & $2 / 17$ & $2 / 16$ & Drop & Drop \\
\hline Share all relevant concerns (modification) & $9 / 17$ & $13 / 16$ & & Retain \\
\hline Remove "disclose relevant concerns" from this habit & 0 & Drop & & Drop \\
\hline Articulate priorities (original) & $9 / 17$ & $6 / 16$ & $2 / 16$ & Drop \\
\hline $\begin{array}{l}\text { State which concerns are most important } \\
\text { (modification) }\end{array}$ & $8 / 17$ & $10 / 16$ & $14 / 16$ & Retain \\
\hline Remove "articulate priorities" from this habit & 0 & Drop & & Drop \\
\hline Approve or modify stated agenda (addition) & $10 / 16$ & $15 / 16$ & & Retain \\
\hline Set the agenda for the visit (addition) & $11 / 17$ & $11 / 16$ & $9 / 16$ & -- \\
\hline Solicit the physician's goals for the visit (addition) & $7 / 16$ & $4 / 16$ & Drop & Drop \\
\hline Explain how one learns best (addition) & $3 / 16$ & Drop & & Drop \\
\hline Greet or verbally welcome the physician (addition) & $11 / 16$ & $13 / 16$ & & Retain \\
\hline
\end{tabular}

\section{Habit 2: Provide your perspective}

\begin{tabular}{|c|c|c|c|c|}
\hline Express preferences (original) & $14 / 17$ & & & Retain \\
\hline Share values (modification) & $2 / 17$ & Drop & & Drop \\
\hline Remove "express preferences" from this habit & $1 / 17$ & & & Drop \\
\hline Express expectations (original) & $5 / 17$ & $5 / 16$ & $9 / 16$ & -- \\
\hline State specific requests (modification) & $2 / 17$ & $1 / 16$ & $1 / 16$ & -- \\
\hline Share wishes and expectations (modification) & $5 / 17$ & $5 / 16$ & $2 / 16$ & -- \\
\hline $\begin{array}{l}\text { Express hopes, desires, and expectations } \\
\text { (modification) }\end{array}$ & $5 / 17$ & $5 / 16$ & $4 / 16$ & -- \\
\hline Remove "express expectations" from this habit & 0 & & & Drop \\
\hline Describe impact (original) & $2 / 17$ & & & Drop \\
\hline Tell how illness affects daily life (modification) & $15 / 17$ & & & Retain \\
\hline Remove "describe impact" from this habit & 0 & & & Drop \\
\hline Participate in visit (original) & $6 / 17$ & $7 / 16$ & $7 / 16$ & -- \\
\hline $\begin{array}{l}\text { Provide details about symptoms, concerns, and } \\
\text { previous treatments (modification) }\end{array}$ & $3 / 17$ & $6 / 16$ & $4 / 16$ & -- \\
\hline $\begin{array}{l}\text { Give opinions about possible causes of illness } \\
\text { (modification) }\end{array}$ & 0 & & & Drop \\
\hline
\end{tabular}


Table 3: Results of the Delphi ratings by round (Continued)

\begin{tabular}{|c|c|c|c|c|}
\hline $\begin{array}{l}\text { Answer questions in reasonable detail, raise new } \\
\text { comments, demonstrate respect (modification) }\end{array}$ & $3 / 17$ & 0 & & Drop \\
\hline Remove "participate in visit" from this habit & $5 / 17$ & $3 / 16$ & $5 / 16$ & -- \\
\hline Tell story (original) & $7 / 17$ & $8 / 16$ & $12 / 16$ & Retain \\
\hline $\begin{array}{l}\text { Offer information about medical history } \\
\text { (modification) }\end{array}$ & $1 / 17$ & 0 & & Drop \\
\hline Tell the whole story of illness (modification) & $3 / 17$ & $2 / 16$ & 0 & Drop \\
\hline Tell the whole story of your concern(s) (modification) & $3 / 17$ & $3 / 16$ & 0 & Drop \\
\hline $\begin{array}{l}\text { Tell story with answers to Kleinman's explanatory } \\
\text { model questions (modification) }\end{array}$ & $2 / 17$ & $2 / 16$ & $1 / 16$ & Drop \\
\hline Remove "tell story" from this habit & $1 / 17$ & $1 / 16$ & $3 / 16$ & Drop \\
\hline $\begin{array}{l}\text { Explain personal beliefs or worries about symptoms } \\
\text { (addition) }\end{array}$ & $15 / 15$ & & & Retain \\
\hline $\begin{array}{l}\text { Honestly point out when areas are left unaddressed } \\
\text { (addition) }\end{array}$ & $7 / 15$ & $11 / 16$ & $15 / 16$ & Retain \\
\hline $\begin{array}{l}\text { State own understanding of problem (explanatory } \\
\text { model) with physician (addition) }\end{array}$ & $11 / 17$ & $14 / 16$ & & Retain \\
\hline Give frank opinions about choices offered (addition) & $9 / 16$ & $15 / 16$ & & Retain \\
\hline Offer explanations (addition) & $3 / 15$ & & & Drop \\
\hline $\begin{array}{l}\text { Ask questions about explanations and choices } \\
\text { (addition) }\end{array}$ & $13 / 17$ & & & Retain \\
\hline
\end{tabular}

\section{Habit 3: Communicate about your feelings and concerns}

\begin{tabular}{|c|c|c|c|c|}
\hline Express feelings and concerns (original) & $8 / 17$ & $13 / 16$ & & Retain \\
\hline $\begin{array}{l}\text { Discuss psychosocial issues and express feelings and } \\
\text { concerns (modification) }\end{array}$ & $3 / 17$ & 0 & & Drop \\
\hline $\begin{array}{l}\text { Express and elaborate on feelings and concerns } \\
\text { (modification) }\end{array}$ & $6 / 17$ & $3 / 16$ & & Drop \\
\hline $\begin{array}{l}\text { Remove "express feelings and concerns" from this } \\
\text { habit }\end{array}$ & 0 & & & Drop \\
\hline $\begin{array}{l}\text { Explore impact of feelings and concerns on health } \\
\text { (addition) }\end{array}$ & $5 / 16$ & $7 / 16$ & $9 / 16$ & -- \\
\hline $\begin{array}{l}\text { Respond to physician's expression of empathy } \\
\text { (addition) }\end{array}$ & $5 / 15$ & $4 / 16$ & & Drop \\
\hline Talk openly about psychosocial issues (addition) & $7 / 16$ & $13 / 16$ & & Retain \\
\hline Listen to physician for understanding (addition) & $4 / 16$ & & & Drop \\
\hline
\end{tabular}

Habit 4: Invest in the end

Use own language and terms to describe diagnosis (original)

Use own language and terms to describe diagnosis evaluation or treatment plans (modification)

Remove "use own language and terms to describe diagnosis" from this habit

\section{$1 / 17$}

Drop

$12 / 17$

Retain

$4 / 17$
Drop 
Table 3: Results of the Delphi ratings by round (Continued)

\begin{tabular}{|c|c|c|c|c|}
\hline $\begin{array}{l}\text { Express level of participation in decision making } \\
\text { desired and participate to that extent (modification) }\end{array}$ & $8 / 17$ & $10 / 16$ & $11 / 16$ & -- \\
\hline $\begin{array}{l}\text { Make opinions or concerns about choices known } \\
\text { (modification) }\end{array}$ & $2 / 17$ & $1 / 16$ & $1 / 16$ & -- \\
\hline $\begin{array}{l}\text { State preferences about tests or treatment options } \\
\text { (modification) }\end{array}$ & $4 / 17$ & $1 / 16$ & $2 / 16$ & -- \\
\hline $\begin{array}{l}\text { Remove "participate in decision making" from this } \\
\text { habit }\end{array}$ & 0 & & & Drop \\
\hline $\begin{array}{l}\text { Restate recommendations and information provided } \\
\text { by doctor (original) }\end{array}$ & $8 / 17$ & $9 / 16$ & $13 / 16$ & Retain \\
\hline Restate decisions made during the visit (modification) & $8 / 17$ & $5 / 16$ & $2 / 16$ & Drop \\
\hline $\begin{array}{l}\text { Remove "restate recommendations and information } \\
\text { provided by doctor" from this habit }\end{array}$ & $1 / 17$ & $2 / 16$ & $1 / 16$ & Drop \\
\hline Ask questions (original) & $17 / 17$ & & & Retain \\
\hline Remove "ask questions" from this habit & 0 & & & Drop \\
\hline Seek clarifying information (original) & $16 / 17$ & & & Retain \\
\hline Remove "seek clarifying information" from this habit & $1 / 17$ & & & Drop \\
\hline $\begin{array}{l}\text { Describe any barriers to following the treatment plan } \\
\text { (addition) }\end{array}$ & $14 / 16$ & & & Retain \\
\hline $\begin{array}{l}\text { Ask the doctor to explain any words or ideas that are } \\
\text { confusing (addition) }\end{array}$ & $13 / 17$ & & & Retain \\
\hline Explore barriers to implementing the plan (addition) & $8 / 17$ & $12 / 16$ & & Retain \\
\hline Answer the "Ask me 3" questions (addition) & $7 / 17$ & $7 / 16$ & $15 / 16$ & Drop \\
\hline $\begin{array}{l}\text { Ask about options interested in but not mentioned by } \\
\text { the doctor (addition) }\end{array}$ & $13 / 17$ & & & Retain \\
\hline
\end{tabular}

across the habits, with 4 behaviors in Habit 1, 8 in Habit 2; 2 in Habit 3, and 8 in Habit 4. At the same time, 34 behaviors were dropped and consensus was not reached for 17 items. The project team reviewed and made minor revisions to the retained behaviors that reached consensus and to the names of the habits so they reflected the patients' perspective. The list of patient behaviors was distributed to the experts for their review and feedback. Of the 12 experts who provided feedback, nearly all stated that they were comfortable with the final list of patient behaviors and with the Delphi process overall. Two experts expressed concerns about not including "participate in decision making" in the final list; this was among the behaviors that did not reach consensus. Table 4 presents a proposed framework that includes patient habits and communication behaviors (columns 1 and 2) derived from our consensus process as well as physician habits and communication behaviors (columns 3 and 4) from the original Four Habits Model.

\section{Discussion}

Although several investigators have described the physician $[6,23,24]$ and patient [24-26] communication behaviors that are desirable elements of patient-centered communication, the literature lacks a generally-accepted model for how both sets of behaviors might unfold and influence the course and outcome of a clinical encounter. An overarching model of patient-physician communication might prompt researchers to examine the degree to which interventions directed toward one party (i.e., either 
Table 4: Patient communication behaviors identified through expert consensus and physician communication behaviors within the Four Habits Model Framework

\begin{tabular}{|c|c|c|c|}
\hline \multicolumn{2}{|c|}{$\leftarrow$ Consensus Behaviors $\rightarrow$} & \multicolumn{2}{|c|}{$\leftarrow$ Original Four Habits Model $\rightarrow$} \\
\hline Patient Habit & Patient behaviors & Physician Habit & Physician behaviors \\
\hline Invest in the beginning & $\begin{array}{l}\text { Greet or verbally welcome } \\
\text { health care provider } \\
\text { Share all relevant concerns } \\
\text { State which concerns are most } \\
\text { important } \\
\text { Approve or modify agenda }\end{array}$ & Invest in the beginning & $\begin{array}{l}\text { Create rapport quickly } \\
\text { Elicit the patient's concerns } \\
\text { Plan the visit with the patient }\end{array}$ \\
\hline Provide your perspective & $\begin{array}{l}\text { Share your story } \\
\text { State own understanding of } \\
\text { problem } \\
\text { Tell how illness affects daily } \\
\text { life } \\
\text { Explain personal beliefs or } \\
\text { worries about symptoms } \\
\text { Express preferences (such as } \\
\text { desires for specific tests, } \\
\text { treatment, decision making) }\end{array}$ & $\begin{array}{l}\text { Elicit the patient's } \\
\text { perspective }\end{array}$ & $\begin{array}{l}\text { Ask for the patient's ideas } \\
\text { Elicit specific requests } \\
\text { Explore the impact on the } \\
\text { patient's life }\end{array}$ \\
\hline $\begin{array}{l}\text { Communicate about your } \\
\text { feelings and concerns }\end{array}$ & $\begin{array}{l}\text { Express feelings and concerns } \\
\text { Talk openly about } \\
\text { psychosocial issues (such as } \\
\text { anxiety, fear, sadness) } \\
\text { Indicate if areas have not been } \\
\text { addressed } \\
\text { Ask healthcare provider to } \\
\text { explain any words or ideas } \\
\text { that are confusing }\end{array}$ & Demonstrate empathy & $\begin{array}{l}\text { Be open to patient's emotions } \\
\text { Make at least one empathic } \\
\text { statement } \\
\text { Convey empathy nonverbally } \\
\text { Be aware of your own } \\
\text { reactions }\end{array}$ \\
\hline Invest in the end & $\begin{array}{l}\text { Use own words to summarize } \\
\text { information and } \\
\text { recommendations provided } \\
\text { by the health care provider } \\
\text { Ask questions about } \\
\text { explanations and choices } \\
\text { Give frank opinions about } \\
\text { choices offered } \\
\text { Describe or explore any } \\
\text { barriers to following } \\
\text { recommendations } \\
\text { Ask about options interested } \\
\text { in but not mentioned by the } \\
\text { health care provider } \\
\text { Conclude visit }\end{array}$ & Invest in the end & $\begin{array}{l}\text { Deliver diagnostic information } \\
\text { Provide education } \\
\text { Involve patient in decision } \\
\text { making } \\
\text { Complete the visit }\end{array}$ \\
\hline
\end{tabular}

Columns 1 and 2 represent patient behaviors identified in the consensus process involving experts in communication research

Columns 3 and 4 represent the original Four Habits Model (Stein, Frankel, Krupat) 
physicians or patients) influence the communication behaviors of the interaction partner. Moreover, a framework that describes the sequence of communication behaviors could help guide interventions directed toward specific segments of the interaction. The Four Habits Model has been particularly useful in describing the appropriate physician communication behaviors during the course of a clinical interaction and serving as a research framework for interventions promoting patientcentered communication skills among physicians [9]. We believed that this Model could serve as a useful starting point for developing a framework that includes both physician and patient communication behaviors. As a first step in this direction, we conducted a consensus process involving a group of communication experts to identify an initial set of patient communication behaviors that could affect the course, direction and outcomes of the medical encounter.

Seventeen international experts in communication research, medical education and health care delivery participated in the consensus process. We found the Delphi method useful in soliciting input and building consensus within this group. The experts were quite engaged throughout the entire process, as evidenced by the numerous suggestions ( 25 modifications, 20 additions) they made in round 1 and the greater than $90 \%$ response rate to all three rounds of ratings. Most of their suggestions pertained to Habit 2 ("Provide your perspective") with Habit 3 ("Communicate your feelings and concerns") receiving the least number of suggestions.

After three rounds of ratings, the experts agreed to retain 22 behaviors which were distributed throughout the Model. Interestingly, 6 behaviors that the experts agreed to retain were among the 14 originally-proposed by the project team. The final list addresses key aspects of patient communication, such as sharing and prioritizing concerns, expressing feelings, and summarizing information and recommendations provided by the physician. While most behaviors can be assessed using existing coding schemes, the list also includes a few behaviors that may require methods that examine the content of statements made by the patient. Examples of such behaviors include "describe how the illness affects (one's) daily life" and "share your story".

Of the behaviors that the experts agreed to drop or which ultimately did not achieve consensus (in either direction), most were similar to other behaviors that were retained. For example, "give opinions about possible causes of (my) illness," a suggestion that received 0 votes, is comparable to "state own understanding of the problem," a retained behavior. Similarly, "respond to the clinician's welcome," which did not achieve consensus is comparable to the retained behavior, "greet or verbally welcome the physician." Several experts also noted that certain behaviors were not practical for the typical patient (e.g., "solicit the physician's goals for the visit"), which may explain why they were dropped from the Model.

The experts were unable to reach consensus on whether or not to retain "participate in decision-making" or any of its suggested modifications. Interestingly, the literature lacks a detailed definition of what constitutes patient participation or involvement in decision making $[27,28]$. In a recent study of physician-patient communication related to breast cancer decisions, Brown and colleagues [29] assessed whether the patient: presented her agenda; declared her preferences (for information and involvement); declared her perspectives (costs and benefits of treatment); and portrayed herself in an active role. To a certain extent, these elements were retained, even though they are not labeled as participation in decisionmaking. For example, Habit 2 includes: "express preferences...". Similarly, Habit 4 includes: "use own words to summarize information...," "give frank opinions about the choices offered," "ask questions about explanations and choices," "describe any barriers to following recommendations," and "ask about options interested in but not mentioned by the health care provider".

The following limitations should be considered when reviewing our findings. First, our project focused on verbal communication behaviors only because we believe that these behaviors might serve as a logical starting point for developing educational initiatives for patients. Second, our results should not be interpreted as representing all the views of experts in the field of communication, particularly patient communication. Our panel included those with expertise in developing interventions to enhance physician communication as well as those who focus specifically on improving patient communication skills. We chose experts with diverse interests to acknowledge the interactive nature of physician-patient communication (i.e., to recognize that the physician's communication behaviors influences the patients' communication behaviors).

Third, it is important to note that the Four Habits Model describes a set of basic physician communication behaviors for the clinical encounter. Studies of the medical interview which were conducted in primary care with adult patients, other conceptual models of communication and consensus statements (i.e., Kalamazoo consensus statement) informed the development of the Four Habits Model $[9,30]$. Thus, the original model and patient behaviors suggested through our consensus process may not apply to certain situations, such as communication between physicians and caregivers, pediatric patients, or psychiatric patients. Likewise, the Four Habits Model and our consensus behaviors do not reflect the potential differences in communication styles due to the gender or 
ethnic background of the physician and/or patient. Additional research is necessary to examine (and adapt) the Four Habits Model and the consensus behaviors to these other circumstances.

Finally, our consensus process involved professionals, and we chose this approach for several reasons. Because of our interest in identifying measureable communication behaviors for an overarching conceptual framework, we believed that experts who were familiar with the communication research and education literature would be helpful in generating an initial list in an efficient manner. We also believed that developing the list of patient behaviors was a necessary step for guiding our subsequent work with patients. All 17 experts who participated in the consensus process have years of experience working to enhance the patient's experience of health care, and it is noteworthy that 7 members of the panel were behavioral scientists and not physicians. The fact that the group eliminated behaviors that are not practical for the average patient is a demonstration of their commitment to the patient's perspective.

We recognize that starting with expert opinion could potentially bias the subsequent modification of the communication skills identified through this process and is an important limitation of our study. We also acknowledge that our approach may appear to "privilege" the experts' voice in determining what communication skills and behaviors patients might find useful in communicating with their physicians. By the same token, however, one could argue that a similar bias would exist had we conducted a Delphi process with patients only, not to mention the difficulty that would be entailed in selecting different "types" of patients to participate in such a process. We firmly believe that patients should be involved in the validation process, and this process should involve patient populations: with different demographic characteristics (i.e., gender, race/ethnicity); who are vulnerable (e.g., limited health literacy, older adults, lower socioeconomic status); or with varying degrees of medical comorbidity (i.e., relatively healthy versus relatively complex). Potential approaches could include focus groups or semi-structured interviews with patients, analogous to previous studies which examined patients' perspectives regarding informed decision making [31-33]. In addition, the patient behaviors should be validated using audiotapes of actual encounters, an approach that was used to validate the physician behaviors within the Four Habits Model [8].

\section{Conclusion}

Although much progress has been made in improving physician-patient communication, researchers in the field have tended to focus on either physicians or patients and not consider the interactive nature of communication.
This approach may relate to the lack of an overarching model of physician-patient communication that describes how both sets of behaviors unfold and affect the course and outcome of an interaction. The Four Habits Model is a teaching and research framework that describes the sequence of important physician communication behaviors during the outpatient encounter. Our consensus process involving 17 international experts identified 22 patient verbal communication behaviors which would add the patient's voice to this model. We believe that integrating patient behaviors into the current Four Habits framework is an important step in creating a research and education agenda that could improve communication on both sides of the stethoscope.

\section{Funding information}

Dr Sukumar and Ms. Beauchesne were supported through a contract between the Centers for Disease Control and Prevention and ICF Macro International (Contract Number: 200-2007-M-21989). Drs Rao, Anderson, Stein, and Frankel did not have a financial relationship with ICF Macro International.

\section{Competing interests \\ The authors declare that they have no competing interests.}

\section{Authors' contributions}

$J K R$, LAA, RMF, and BS conceptualized and contributed to the design of this study. JKR worked with BS and DB to collect the data. JKR, LAA, RMF, BS, and TS participated in the analysis and interpretation of the findings. JKR and LAA wrote the first draft of the manuscript, and all authors reviewed and revised drafts of the manuscript. All authors read and approved the final manuscript.

\section{Acknowledgements}

We thank the 17 communication experts who participated in the Delphi process.

\section{Author Details}

'Division of Pharmaceutical Outcomes and Policy, Eshelman School of Pharmacy, University of North Carolina at Chapel Hill, 2202 Kerr Hall, CB 7573, Chapel Hill, NC 27599, USA, 2Healthy Aging Program, Centers for Disease Control and Prevention 4770 Buford Highway NE, MS K-45, Atlanta, GA 30341, USA, ${ }^{3}$ ICF Macro International Inc, 3 Corporate Square, Suite 370, Atlanta, GA 30329, USA, 4The Permanente Medical Group, Kaiser Permanente Northern California, Oakland, CA 94612, USA and ${ }^{5}$ Center for Implementing Evidence Based Practice, Roudebush VA Medical Center, 1481 West 10thStreet, Indianapolis, Indiana, 46202, USA

Received: 9 June 2009 Accepted: 19 April 2010

Published: 19 April 2010

\section{References}

1. Committee on Quality of Health Care in America, Institute of Medicine: Crossing the Quality Chasm Washington DC: National Academy Press; 2001.

2. Kohn LT, Corrigan JM, Donaldson MS, (Eds.): To err is human: Building a safer health system Washington DC: National Academy Press; 2000.

3. Rao JK, Anderson LA, Inui TS, Frankel RM: Communication interventions make a difference in conversations between physicians and patients: a systematic review of the evidence. Medical Care 2007, 45:353-362.

4. Inui TS, Carter WB: Problems and prospects for health services research on provider-patient communication. Medical Care 1985, 23:521-538.

5. Stein TS, Kwan J: Thriving in a busy practice: physician-patient communication training. Effective Clinical Practice 1999, 2:63-70. 
6. Frankel RM, Stein T: Getting the most out of the clinical encounter: The Four Habits Model. Journal of Medical Practice Management 2001, 16:184-191.

7. Frankel RM, Stein T, Krupat E: The four habits approach to effective clinical communication Oakland, California: Kaiser Permanente Northern California Region: Physician Education and Development; 2003.

8. Krupat E, Frankel RM, Stein T: The Four Habits coding scheme: Validation of an instrument to assess clinicians' communication behavior. Patient Education and Counseling 2006, 62:38-45.

9. Stein T, Frankel RM, Krupat E: Enhancing clinician communication skills in a large healthcare organization: A longitudinal case study. Patient Education \& Counseling 2005, 58:4-12.

10. Tallman K, Janisse T, Frankel RM, Sung SH, Krupat E, Hsu J: Communication practices of physicians with high satisfaction ratings. The Permanente Journal 2006, 11:19-29.

11. Gulbrandsen P, Krupat E, Benth JS, Garratt A, Safran DG, Finset A, Frankel RM: "Four Habits" goes abroad: Report from a pilot study in Norway. Patient Education and Counseling 2008, 72:388-393.

12. deVilliers MR, deVilliers PJT, Kent AP: The Delphi technique in health sciences education research. Medical Teacher 2005, 27:T639-643.

13. Fink A, Kosecoff J, Chassin M, Brook RH: Consensus methods: Characteristics and quidelines for use. American Journal of Public Health 1984, 74:979-983.

14. de Meyrick J: The Delphi method and health research. Health Education 2002, 103:7-16.

15. Hsu C-C, Sandford BA: The Delphi technique: making sense of consensus. Practical Assessment, Research and Evaluation 2007:12.

16. Powell C: The Delphi technique: Myths and realities. Journal of Advanced Nursing 2003, 41:376-382

17. Shaw MD, Coggin C: Using a Delphi technique to determine the needs of African American breast cancer survivors. Health Promotion Practice 2008, 9(1):34-44

18. Hasson F, Keeney S, McKenna H: Research quidelines for the Delphi survey technique. Journal of Advanced Nursing 2000, 32:1008-1015.

19. Jones J, Hunter D: Qualitative research: consensus methods for medical and health services research. British Medical Journal 1995, 311:376-380.

20. Campbell SM, Braspenning J, Hutchinson A, Marshall MN: Research methods used in developing and applying quality indicators in primary care. British Medical Journal 2003, 326:816-819.

21. Delbecq AL, Ven AH Van de, Gustafson DH: Group techniques for program planning: A guide to nominal and Delphi processes Glenview, IL: Scott, Foresman; 1975

22. Kleinman A: Culture, illness and cure: Clinical lessons from anthropologic and cross-cultural research. Annals of Internal Medicine 1978, 88:251-258

23. Cole SA, Bird J: The Medical Interview. The three-function approach St. Louis, MO: Mosby, Inc; 2000

24. Roter DL, Hall JA: Physician gender and patient-centered communication. A critical review of empirical research. Annual Review of Public Health 2004, 25:497-519.

25. Greenfield S, Kaplan S, Ware JE Jr: Expanding patient involvement in care. Effects on patient outcomes. Annals of Internal Medicine 1985, 102(4):520-528.

26. Street RL: Active patients as powerful communicators. In The New Handbook of Language and Social Psychology Edited by: Robinson WP, Giles H. Chichester: John Wiley \& Sons; 2001:541-560.

27. Elwyn G, Edwards A, Mowle S, Wensing M, Wilkinson C, Kinnersley P, Gro $R$ : Measuring the involvement of patients in shared decision making: a systematic review of instruments. Patient Education and Counseling 2001, 43:5-22

28. Moumjid N, Gafni A, Bremond A, Carrere M-O: Shared decision making in the medical encounter: are we all taking about the same thing? Medical Decision Making 2007, 27:539.

29. Brown RF, Butow PN, Sharrock MA, Henman M, Boyle F, Goldstein D, Tattersall MHN: Education and role modeling for clinical decisions with female cancer patients. Health Expectations 2004, 7:303-316.

30. Makoul G: Essential elements of communication in medical encounters: The Kalamazoo Consensus Statement. Academic Medicine 2001, 76:390-393

31. Haidet $P$, Kroll TL, Sharf BF: The complexity of patient participation: lessons learned from patients' illness narratives. Patient Education and Counseling 2006, 62:323-329.
32. Entwistle V, Prior M, Skea ZC, Francis JJ: Involvement in treatment decision making: its meaning to people with diabetes and implications for conceptualization. Social Science and Medicine 2008, 66:362-375.

33. Thompson AGH: The meaning of patient involvement and participation in health care consultations: A taxonomy. Social Science and Medicine 2007, 64:1297-1310

\section{Pre-publication history}

The pre-publication history for this paper can be accessed here: http://www.biomedcentral.com/1472-6963/10/97/prepub

doi: 10.1186/1472-6963-10-97

Cite this article as: Rao et al., Engaging communication experts in a Delph process to identify patient behaviors that could enhance communication in medical encounters BMC Health Services Research 2010, 10.97

\section{Submit your next manuscript to BioMed Central and take full advantage of:}

- Convenient online submission

- Thorough peer review

- No space constraints or color figure charges

- Immediate publication on acceptance

- Inclusion in PubMed, CAS, Scopus and Google Scholar

- Research which is freely available for redistribution

Submit your manuscript at www.biomedcentral.com/submit
C Biomed Central 